\title{
An Empirical Study on the Environmental Effects of Industrial Spatial Agglomeration Since the Reform and Opening-up
}

\author{
S.R. Yan*, H. L. Huang*, W. H. Li*, L.N. Wang*, M.W. Tian* and H.P. Yan**† \\ *College of Accounting and Finance, Jiangxi University of Engineering, Xinyu 338000, China \\ **School of Marxism, Hainan University, Haikou 570228, China \\ †Corresponding author: H.P. Yan; glx682@163.com
}

\section{Nat. Env. \& Poll. Tech. Website: www.neptjournal.com \\ Received: 17-09-2019 \\ Revised: 23-10-2019 \\ Accepted: 11-12-2019 \\ Key Words: \\ Industrial spatial agglomeration \\ Pollution haven hypothesis \\ Environmental policy}

\begin{abstract}
In the past 40 years after China adopted the reform and open-up policy, China's expediting industries spatial agglomeration has resulted in severe damage to the environment. In China, the one whether the pollution haven hypothesis $(\mathrm{PHH})$ is true or not is the hot issue under the research of academic circles. By establishing the mechanism model of industries spatial agglomeration and environmental pollution in this paper, we discovered upon our empirical study that China's industrial spatial agglomeration process had apparent threshold characteristics for environmental pollution, those direct investment and scientific innovation of foreign merchants apparently improved environmental pollution, so $\mathrm{PHH}$ is not true in China and such conclusion provides empirical support for China's industrial agglomeration and environmental policymaking. At the end of the paper, the policy proposals for improving environmental pollution in future are made, which have important significance for China's high-quality economic development.
\end{abstract}

\section{INTRODUCTION}

Since China adopted the reform and open-up policy 40 years ago, China's expediting industries spatial agglomeration and extensive economy growth caused severe damage to the environment. In China, whether the pollution haven hypothesis $(\mathrm{PHH})$ is true or not is the hot issue under the research of academic circles. Facing a series of severe environmental pollution problems, the Chinese government at all levels have promulgated a series of environmental protection policies in succession, but the environmental pollution problems are still serious (Yamashita et al. 2014). In recent years, the emission of all kinds of pollutants in China has been increasing. However, emission of all kinds of pollutants is reducing in certain regions as the regional industrial agglomeration level improves, which is rightly different from those at the national levels (Shao et al. 2017). Logically, pollutant emission is the inevitable product of industrial development, and industrial agglomeration development is certainly correlated with environmental pollution; both of different phenomena aforesaid provide a better research perspective, namely the one whether the industrial agglomeration intensifies or improves environmental pollution. Based on this question, a research was made in this paper and the theoretical model for the impact of industrial agglomeration on environmental pollution was further discussed, which provides a theoretical support for recognizing correctly the relationship between industrial agglomeration and environmental pollution. Meanwhile, the data of 30 provinces and municipalities (autonomous regions) of China from 2009 to 2016 were used to analyse the impact of industrial agglomeration on environmental pollution, such objective evaluation on the function of industrial agglomeration on environmental pollution will benefit to realize the national objective of energy conservation and emission reduction, and provide a new perspective and thinking for the systematic engineering of improving the environmental pollution of China (Ning et al. 2016).

Previous researches were conducted based on the complicated relationship between industrial agglomeration and environmental pollution, and uncertain external effect of industrial agglomeration for the environment (Almulali et al. 2015). There was a lack of support of the theoretical model for the relationship between industrial agglomeration and environmental pollution, and previous researches were made based on the linear models (Baek et al. 2009). Based on which, the research in this paper was made from the following three aspects. Firstly on the theoretical level, the Copeland-Taylor model was borrowed in this paper to construct a theoretical model for the impact of industrial agglomeration on environmental pollution, and thereby the relationship between industrial agglomeration and environmental pollution was further analysed (Ottaviano et al. 2002); secondly on the perspective level, the threshold effect 
of industrial agglomeration on environmental pollution was investigated and the existence and range of threshold effect was analysed from the perspective of industrial agglomeration threshold (Zeng \& Zhao 2009); lastly on the level of methodology, the threshold panel model was adopted in this paper to make analysis, which is rightly different from the previous and non-linear approaches adopted by previous researches, such as the cross term regression (Virkanen, 1998, Frank 2001). Moreover in the paper, a further and more objectively analysis on the impact of China's industrial agglomeration on environmental pollution was made by adopting the threshold panel model and by comparing with the linear approaches (Walter \& Ugelow 1979, Stiebale 2011, Venables 1996).

\section{THEORETICAL MODEL}

By borrowing the Copeland-Taylor model in this paper, a theoretical model for the impact of industrial agglomeration on environmental pollution was established.

\section{Production Function}

Hypothesizing that a community produces two kinds of products, namely the cleaning product $\mathrm{Y}$ and the capital-intensive pollution product $\mathrm{X}$, where the production of pollution product $\mathrm{X}$ produces the environmental pollutant $\mathrm{Z}$, which causes not only the negative external effect but also produces social cost. In view of the clearly defined property right, enterprises must pay the corresponding cost for the emission of pollutants; in reality, the corresponding cost is represented by the environment tax, pollutant charge or pollutant discharging license fee. Enterprise aims at pursuing the maximized profit; where the one that enterprise discharges pollutant randomly is not the best optimal choice; instead, a portion of production factors are used for reducing pollutant emission. Hypothesizing that the percentage of the production factor used by enterprises for governing pollution to the total production factors is $\gamma$, where $0 \leq \gamma \leq 1$. When $\gamma=0$, it means the one that enterprise does not govern pollution; at this moment, the yield of enterprise is the potential yield $\mathrm{F}$ of the enterprise; when $0<\gamma<1$, it means the one that enterprise uses the production factors at the percentage of $\gamma$ to govern pollutants; at this moment, the actual yield of enterprise is $(1-\gamma) F$ and meanwhile the pollutant $\mathrm{Z}$ will generate, so:

$$
\begin{gathered}
X=(1-\gamma) F \\
Z=\phi(\gamma) F \\
\phi(\gamma)=\frac{1}{A}(1-\gamma)^{\frac{1}{a}}
\end{gathered}
$$

Here $\phi(\gamma)$ is the pollution discharge function for $\gamma$, and is the decreasing function of $\gamma, \mathrm{A}$ is the production technology, and the parameter $\mathrm{a} \in(0,1)$.
Hypothesizing the production factor is the capital $\mathrm{K}$ and the labour L, so the production function is expressed respectively in the one as follows:

$$
\begin{gathered}
X=(1-\gamma) F\left(\mathrm{k}_{X}, L_{X}\right) \\
Y=H\left(K_{Y}, L_{Y}\right) \\
Z=\phi(\gamma) F\left(K_{X}, L_{X}\right)
\end{gathered}
$$

Hence,

$$
\begin{aligned}
& Z=\frac{1}{A}(1-\gamma)^{\frac{1}{a}} F\left(K_{X}, L_{X}\right) \\
& X=(A Z)^{\mathrm{a}}\left[F\left(K_{X}, L_{X}\right)\right]^{1-\mathrm{a}}
\end{aligned}
$$

\section{Production Decision}

Hypothesizing the one that enterprise produces $\mathrm{X}$ and wants maximized profit, the decision at this moment can be made by two independent processes (Lee 2007). On one hand, in the circumstances that the given capital cost is $r$ and the labour pay is $\mathrm{w}$, the enterprise will select an optimal capital-labour ratio to realize the minimized production $\operatorname{cost} C_{F}$ of unit potential output. On the other hand, in the circumstances that the given unit potential production cost is $\mathrm{C}_{\mathrm{F}}$ and the pollution discharge cost is $\gamma$, the optimal combination of the potential output $\mathrm{F}$ and the pollution discharge $\mathrm{Z}$ will be selected to realize the minimized production $\cos t C_{X}$ required by the realization of unit product $\mathrm{X}$, so:

$$
\begin{gathered}
C_{F}(r, w)=\min \left\{r a_{K F}+w a_{L F}, F\left(a_{K F}, a_{L F}\right)=1\right\} \\
C_{X}\left(\lambda, C_{F}\right)=\min \left\{\lambda A Z+C_{F} F,(A Z)^{a} F^{1-a}=1\right\}
\end{gathered}
$$

By solving the Equations (9) and (10) on the optimal level, we can obtain:

$$
\begin{gathered}
T R S_{K L}=\frac{\partial F}{\partial K_{X}} \cdot \frac{\partial F}{\partial L_{X}}=\frac{r}{w} \\
\frac{(1-a) A Z}{a F}=\frac{C_{F}}{\lambda}
\end{gathered}
$$

\section{Decision on Pollution Discharge}

Hypothesizing the price of product $\mathrm{X}$ is $P_{X}$ and there is perfect competition market, the profit of enterprise will be zero, so:

$$
P_{X} X=c_{\mathrm{F}} F+\lambda(A F)
$$

Based on the Equations (12) and (13), so:

$$
Z=\frac{a P_{X} X}{\lambda A}
$$

Thereby the equation aforesaid can be re-written as: 


$$
Z=\left(P_{X} X+P_{Y} Y\right) \frac{a}{\lambda A} \frac{P_{X} X}{\left(P_{X} X+P_{Y} Y\right)}
$$

So:

$$
Z=S \frac{a}{\lambda A} \mu_{X}
$$

Where $S=P_{X} X+P_{Y} Y$ stands for the scale factor; $\mu_{X}=\frac{P_{X} X}{\left(P_{X} X+P_{Y} Y\right)}$ stands for the percentage of product $\mathrm{X}$ to the total value of output, namely the structural factor.

Take the logarithm for both sides of the Equation (16), so:

$$
\ln Z=\ln S+\ln a+\ln \mu_{X}-\ln A-\ln \lambda
$$

Industrial agglomeration will affect the industrial scale and will affect technological advancement through inter-industry overflow effect, and will further affect the regional economic structure. If so, the impact of industrial agglomeration on industrial scale, technological advancement and economic structure can be expressed in the one as follows:

$$
\begin{gathered}
S=S^{\prime}(\text { aggl }) \\
A=A^{\prime}(a g g l) \\
\mu_{X}=\mu_{X}^{\prime}(\operatorname{aggl})
\end{gathered}
$$

Industrial agglomeration (aggl) impacts emission degree of pollutant through three levels, i.e., S, A and $\mu_{X}$ (in the Equation 17), so the model can be further re-written as the one as follows:

$\ln Z=\ln S^{\prime}(a g g l)+\ln \alpha+\ln \mu_{X}^{\prime}(a g g l)-\ln A^{\prime}(a g g l)-\ln \lambda$

In view of the Equation (21), we can find that there is a complicated relationship between industrial agglomeration (aggl) and environmental pollution, and its influential effect size depends on the size of its impact on $\mathrm{S}, \mathrm{A}$ and $\mu_{X}$, and its function is nonlinear.

\section{MEASUREMENT MODEL, VARIABLE AND DATA}

\section{Setting and Method of Measurement Model}

The analysis in this paper will be conducted based on the threshold panel model of Hansen; the threshold value and quantity of the model will depend completely on the sample data.

The basic form of Hansen threshold is $y_{i}=\beta_{1} x+e_{i}, q_{i} \leq \gamma$ and $y_{i}=\beta_{2} x+e_{i}, q_{i}>\gamma$.

Where, $\mathrm{q}_{\mathrm{i}}$ is the threshold variable, it can be one regression element of explaining variable $\mathrm{X}$, or one independent threshold variable; $\gamma$ is the special threshold value.

In order to obtain the estimated value of the parameter, every observed value will be subtracted from the interclass average value to eliminate the individual effect, so the model can be changed into the one as follows: $y_{i}^{*}=\beta x^{*}(\gamma)+e_{i}^{*} ; y_{i}^{*}=$; $y_{i}-\bar{y}_{i}, x_{i}^{*}=x_{i}-\bar{x}_{i}, e_{i}^{*}=e_{i}-\bar{e}_{i^{\circ}}$.

By piling up all observed values, it can be further changed into the matrix form, i.e.: $Y_{I}^{*}=X^{*}(\gamma) \beta+\mathrm{e}^{*}$.

By using the conditional least square method and by calculating the minimum residual sum of squares $S(\gamma)$, the estimated value of threshold value $\hat{\gamma}$ can be obtained: $\hat{\gamma}=\arg \min _{\gamma} S(\gamma)$.

Through the further calculation, the parameter estimate, residual vector and corresponding residual sum of squares can be obtained.

After obtaining the parameter estimate, the focus process will be the one to conduct the significance test on the threshold effect and threshold estimate. The original hypothesis of threshold effect significance test is $H_{0}: \beta_{1}=\beta_{2}$, the test statistics is $F_{1}=\left[S_{0}-S(\hat{\gamma})\right] / \hat{\sigma}^{2}, \mathrm{~S}_{0}$ is the residual sum of squares obtained from the original hypothesis $\mathrm{H}_{0}$. There is no way to identify the threshold value $\gamma$ in the original hypothesis $\mathrm{H}_{0}$. If so, the distribution of $\mathrm{F}_{1}$ statistics is non-standard. To acquire its asymptotic distribution, Hansen (1999) proposed to use the "self-sampling method" and further establish its $\mathrm{P}$ value; the original hypothesis of threshold estimate significance test is $H_{0}: \hat{\gamma}=\gamma_{0}$, so the corresponding likelihood ratio test statistic is $L R_{1}=[S(\gamma)-S(\hat{\gamma})] / \hat{\sigma}^{2}$, and its distribution is non-standard. Therefore, Hansen (1999) proposed to establish a confidence interval for $\gamma$, and provide a simple formula $L R_{1}\left(\gamma_{0}\right) \leq c(a)$, wherein the equation of $c(a)=-2 \ln (1-\sqrt{1-a})$, a is the significance level.

The parameter estimates and significance test aforesaid focused on the single threshold model. If there are two or more threshold values in the model, there is a need to extend the model. In accordance with the threshold model of Hansen, the model is hypothesized in the paper as follows: $\ln P_{i t}=a_{i}+\beta_{1} a g g l_{i t} \cdot I\left(\right.$ thre $\left._{i t} \leq \gamma\right)+\beta_{2} \operatorname{aggl}_{i t}\left(\right.$ thre $\left._{i t}>\gamma\right)+\beta_{n} X+\varepsilon_{\mathrm{it}} \cdot$

Where, $\mathrm{P}$ is the pollutant discharge, aggl is the industrial agglomeration, $\mathrm{X}$ is a group of other control variables affecting environmental pollution, especially the direct investment of foreign merchant, environmental regulation, energy con- 
sumption and technological innovation; the subscripts i and $\mathrm{t}$ stand respectively for the region and year, and there is the threshold variable, $\gamma$ is the threshold value, and $I(\cdot)$ is the indicator function.

\section{Variable Selection and Data Description}

Pollutant discharge (P): In reality, pollutant discharge includes mainly atmospheric pollution, water pollution, waste pollution and noise pollution. In view of the existing research, the one how to establish a comprehensive pollution index is used to reflect the one that there is no awareness consensus for the overall pollution of a region; therefore, more researches use the specific pollution indicators. Currently, China is the country in which the sulphur dioxide is discharged maximally, which is the main component of atmospheric pollutant, and the data has higher reliability. In this paper, the total discharge of industrial sulphur dioxide is used as the measuring indicator of pollution discharge.

Industrial agglomeration level (aggl): The measurement index of industrial agglomeration includes Hoover index, E-G index, Gini coefficient, location quotient, etc.; all of these indexes have certain merits and demerits. However, since the location quotient can reflect the spatial distribution of geographic elements authentically and relieve the regional scale error factor, it is used by most of the scholars at home and abroad. The calculation formula of the location quotient aggl of the industry $r$ in the region $i$ is detailed as follows:

$$
a g g l=\left(\frac{e_{i r}}{\sum_{i} e_{i t}}\right) /\left(\frac{\sum_{r} e_{i r}}{\sum_{i} \sum_{r} e_{i r}}\right) .
$$

Where, $e_{i r}$ is the total output value of the industry $\mathrm{r}$ in the region i. In this paper, the total industrial output value of various regions was used to calculate the location quotient to measure the industrial agglomeration level of every region.

Other control variables: Direct investment of foreign merchant (fdi): From the perspectives of domestic and overseas researchers, the direct investment of foreign merchant impacts the environmental quality of host country via scale effect, structure effect and technological progress effect. However, certain scholars thought that the direct investment of foreign merchant intensified the environmental pollution of China; but meanwhile, some other scholars thought that the direct investment of foreign merchant improved the environmental pollution of China. Based on which, the influence of the direct investment of foreign merchant on the environment will be investigated in the paper, where the direct investment amount of foreign merchant used by each region in the past years will be used to measure, and these investment amounts will be adjusted into the RMB price according to the intermediary price of foreign exchange in the past years.

Environmental regulation (pr): As the social concern on environmental quality becomes more and more and the weight of environment in governmental appraisal increases, the government will increase the input of environmental governance and protection, whereas the environmental regulation will become severer and severer and enterprise's pollution discharge cost will increase too; if so, the enterprise will be pushed to make technological innovation and which will benefit to reduce environmental pollution. In this paper, the impact of environmental regulation factors on environmental pollution will be investigated by using the total investment amount of every region for the governance of industrial pollution.

Energy consumption (ener): As China's urbanization and industrialization process expedites, China's energy consumption is continuously increasing; moreover, the coal takes up a great proportion in the energy consumption structure of China; meanwhile, the main features of China's industrial development is the high energy consumption and the high emission; therefore, the increasing energy consumption will cause huger stress on the environmental pollution of China. In this paper, the total energy consumption of various regions is adopted to make the measurement.

Technological innovation (sr): Technological innovation will promote technological progress, and technological progress will facilitate enterprise to change production style and optimize structure; thereby enterprise may reduce pollution discharge and improve regional environmental pollution. In this paper, the total R\&D expenditure of industrial enterprises above designated size in every region will be used to make the measurement.

Due to the availability of data, the data of 30 provinces and municipalities of China other than Tibet during the period from 2009 to 2016 were used in this paper to make the analysis. The data required were originated from the Environmental Statistics Yearbook of China, Industrial Economic Statistics Yearbook of China, Statistics Yearbook of China and Statistical Yearbook of other provinces and municipalities in the past calendar years.

\section{EMPIRICAL ANALYSIS}

\section{Threshold Effect Test}

Before determining the form of the model, there is a need to determine the number of thresholds. In view of the practice of Hansen, the industrial agglomeration level (aggl) can be used as the threshold variable, and 1,2 and 3 threshold values are hypothesized to exist, where the corresponding value $\mathrm{F}$ and 
$\mathrm{P}$ are detailed in Table 1. The result showed that the value F of the single threshold is highly significant, and its corresponding value $\mathrm{P}$ is 0.016 ; whereas the corresponding value $\mathrm{F}$ of the dual and triple threshold is not significant, and their corresponding value $\mathrm{P}$ is higher than 0.10 . Thich means the one using the industrial agglomeration level as the threshold variable refuses the original hypothesis of a linear relationship and there is a single threshold effect, which means the one that the relationship between industrial agglomeration and environmental pollution is non-linear.

Furthermore, the threshold value can be obtained; the confidence interval with the threshold estimate of $0.529 \%$ is [0.528, 0.625], see Table 2 for the details. To understand the estimate of the threshold value and the construction process of the confidence interval, the likelihood ratio graph can be used, namely the likelihood ratio function sequence LR $(\gamma)$ serves as the tendency chart of threshold parameter; when the likelihood ratio $\operatorname{LR}(\gamma)$ is 0 , the estimated threshold value $\gamma$ will be equal to 0.529 .

\section{Threshold Model Estimates}

The column II of Table 3 shows the threshold estimate of industrial agglomeration and environmental pollution. From this, it can be seen that the impact of industrial agglomeration on environmental pollution has a remarkable threshold feature. When the industrial agglomeration level is less than 0.529 , the impact of industrial agglomeration on environmental pollution is positive and its coefficient is 0.2805; when the industrial agglomeration level is higher than 0.529 , the impact of industrial agglomeration on environmental pollution gets substantive change and it turns into a negative value, -0.5016 ; it signifies that there is a turning point between industrial agglomeration and environmental pollution. Such a turning point is rightly the threshold value. The relationship between industrial agglomeration and environmental pollution is not a simple linear relationship, and it is rightly different from most of the previous research conclusions. When the industrial agglomeration level is lower than the threshold value, the industrial agglomeration will intensify environmental pollution; the major reason causing this phenomenon is the one that industrial agglomeration scale effect takes up the leading function and it results in the capacity expansion, whereas the technology spillover effect of industrial agglomeration is not remarkable and which results in the one that resource consumption rate exceeds resource regeneration rate and environment's bearing capacity, and finally causes environmental pollution increase. When the industrial agglomeration level exceeds the threshold valve, the industrial agglomeration will turn to improve environmental pollution, which signifies that industrial agglomeration will cause positive external effect on environment; the major reasons causing such a phenomenon are: (1) when industrial agglomeration level improves to a certain extent, industrial agglomeration effect will be higher than crowding effect, which will promote market scale expansion and benefit to enhance scale economy effect and promote industrial production efficiency and management level to improve, and thereby make the pollution discharge of unit output reduce; (2) improvement of industrial agglomeration level will promote regional economic development and improve regional per capita income level; in accordance with the Environment Kuznets Curve, the economic development, when it breaks through specific turn point, will be beneficial to improve environmental pollution; (3) improvement of industrial agglomeration level to a given extent will make the technology spillover effect become remarkable, and technology spill over effect will benefit to push intra-industry enterprise technology advancement, where technology advancement will reduce the pollution discharge of unit output through direct effect and indirect effect, and thereby improve environmental pollution.

In other control variables, the regression coefficient of foreign merchant's direct investment for environmental pollution is negatively significant, which signifies that the

Table 1: Threshold effect test.

\begin{tabular}{|lllllll|}
\hline Item & F-statistics & P-value & BS Number & 1\% Critical value & 5\% Critical value & $10 \%$ Critical value \\
\hline Single threshold & $15.372 * *$ & 0.016 & 400 & 15.208 & 10.501 & 7.502 \\
Double threshold & 3.564 & 0.214 & 400 & 20.086 & 9.076 & 5.683 \\
Triple threshold & 5.419 & 0.108 & 400 & 12.714 & 8.064 & 5.804 \\
\hline
\end{tabular}

Note: $* *$ indicates significant at $5 \%$ level.

Table 2: Results of threshold estimation value.

\begin{tabular}{|lll|}
\hline Item & Threshold Estimation value & 95\% confidence interval \\
\hline Single threshold model & 0.529 & {$[0.528,0.625]$} \\
\hline
\end{tabular}


direct investment of foreign merchant benefits to promote the improvement of environmental pollution of China to some extent, so the "pollution haven hypothesis (PHH)" is not true in China; this conclusion is rightly in conformity with the research conclusions of most of the scholars. The impact coefficient of environmental regulation on environmental pollution is positively significant, it signifies that environmental regulation does not improve China's environmental pollution and which differs from the theoretical analysis expectation. How to understand such a result? In the appraisal of local government, the percentage of environmental factor is increasing gradually, and local government attaches more importance to environmental pollution and therefore increases more investment on the region where it suffers from severe environmental pollution. So, more investment of local government on environmental pollution governance is rightly the representation of the aggravated environmental pollution. To some extent, the more the investment on pollution governance is, the severer the environmental pollution under governance is. The possible reason causing this phenomenon is the one that China's subsidy for environmental pollution governance and China's loan for environmental pollution governance focus only on pollutant governance and control, but both of them have limited incentive for enterprise and thereby the efficiency of investment on environmental pollution governance is not at a high level. The regression coefficient of energy consumption is positive, but it fails to pass the significance test; it signifies that energy consumption has a limited function on environmental pollution and it is not the main factor intensifying environmental pollution. Technological innovation can efficiently improve China's environmental pollution, it signifies technological innovation will promote the research, development and use of new environmental protection technology, which will benefit to improve traditional industry and develop emerging industry, and thereby improve environmental quality.

To make a comparison, the linear model estimate was made for the relationship between industrial agglomeration and environmental pollution in the paper, where the linear model estimate was respectively made by using the fixed effect and the system generalized method of moments (see Row 3-4 of Table 3 for specific results). From the estimated results, it can be seen that industrial agglomeration will result in environmental pollution and the coefficient is higher

Table 3: Estimated results of threshold and linear model.

\begin{tabular}{|c|c|c|c|}
\hline Explanatory Variable & Threshold estimation & $\begin{array}{l}\text { Linear estimation } \\
\text { (FE) }\end{array}$ & $\begin{array}{l}\text { Linear estimation } \\
\text { (SYS-GMM) }\end{array}$ \\
\hline $\operatorname{aggl} . \mathrm{I}(\mathrm{q} \leqq \gamma)$ & $\begin{array}{l}0.2805^{* * * *} \\
(2.94)\end{array}$ & - & - \\
\hline aggl. I ( $\mathrm{q}>\gamma)$ & $\begin{array}{l}-0.5016^{* *} \\
(-2.27)\end{array}$ & - & - \\
\hline aggl & - & $\begin{array}{l}0.3641 * * \\
(2.43)\end{array}$ & $\begin{array}{l}0.4796^{* * * *} \\
(9.84)\end{array}$ \\
\hline $\operatorname{lnfdi}$ & $\begin{array}{l}-0.0061 * * * \\
(-4.34)\end{array}$ & $\begin{array}{l}-0.0203 * * \\
(-2.07)\end{array}$ & $\begin{array}{l}-0.0389 * * * * \\
(-3.46)\end{array}$ \\
\hline $\operatorname{lnpr}$ & $\begin{array}{l}0.1075^{* * * *} \\
(5.37)\end{array}$ & $\begin{array}{l}0.1203 * * * \\
(5.61)\end{array}$ & $\begin{array}{l}0.0206 * * * \\
(5.04)\end{array}$ \\
\hline lnener & $\begin{array}{l}0.0408 \\
(0.64)\end{array}$ & $\begin{array}{l}0.0405 \\
(0.61)\end{array}$ & $\begin{array}{l}0.0397 * * \\
(2.05)\end{array}$ \\
\hline $\operatorname{lnsr}$ & $\begin{array}{l}-0.0587 * * * \\
(-2.65)\end{array}$ & $\begin{array}{l}-0.0802 * * * \\
(-2.79)\end{array}$ & $\begin{array}{l}-0.0407 * * * \\
(-5.73)\end{array}$ \\
\hline cons & $\begin{array}{l}2.764 * * * \\
(7.48)\end{array}$ & $\begin{array}{l}3.0304 * * * \\
(7.61)\end{array}$ & $\begin{array}{l}0.6802 * * * \\
(4.87)\end{array}$ \\
\hline $\begin{array}{l}\text { Abond test } \\
\text { For AR (1) }\end{array}$ & - & - & $\begin{array}{l}-2.894 \\
{[0.007]}\end{array}$ \\
\hline $\begin{array}{l}\text { Abond test } \\
\text { For AR (2) }\end{array}$ & - & - & $\begin{array}{l}0.0365 \\
{[0.865]}\end{array}$ \\
\hline Sargan test & - & - & $\begin{array}{l}23.972 \\
{[0.504]}\end{array}$ \\
\hline
\end{tabular}

Note: Z-statistics are shown in parentheses in the table, and square brackets are P-values; ***, **, and * indicate significant at $1 \%, 5 \%$, and $10 \%$, respectively; the system generalized moment regression model is two-step. 
than the threshold estimate, which is rightly caused by the one that linear model does not consider the difference in the high or low industrial agglomeration level, and different industrial agglomeration level results in the different spillover effect and agglomeration effect, and thereby causes the different functions for environmental pollution. Therefore, the relationship between industrial agglomeration and environmental pollution is the non-linear. If the estimate is made only based on the linear model, it is very much possible to miss important explanation.

\section{CONCLUSION}

In this paper, the Copeland-Taylor model was used to deduce a theoretical model to represent the influencing mechanism of industrial agglomeration for environmental pollution. Based on this, the panel data of 30 provinces and municipalities (autonomous regions) of China during the period from 2009 to 2016, as well as the threshold regression method were used to make empirical analysis on the relationship between industrial agglomeration and environmental pollution. According to the research findings, the relationship between industrial agglomeration and environmental pollution is not a simple linear relationship, but the impact of industrial agglomeration on environmental pollution has remarkable threshold features. When industrial agglomeration level is lower than the threshold value, the industrial agglomeration will intensify environmental pollution; when industrial agglomeration level is higher than the threshold value, the industrial agglomeration will benefit to improve environmental pollution. Additionally, foreign merchant's direct investment and technological innovation will improve environmental pollution to some extent, and $\mathrm{PHH}$ (pollution haven hypothesis) is not true in China; the environmental regulation does not improve China's environmental pollution, and the energy consumption is not the major factor intensifying environmental pollution.

The research conclusions of the paper provide the following policy enlightenments: (1) Manage the relationship between industrial agglomeration and environmental pollution in a dynamic manner. Since a low industrial agglomeration level will intensify environmental pollution, efficient measures should be taken to improve industrial agglomeration level to the threshold valve; once it reaches to the threshold value, environmental pollution can be improved through the threshold effect of industrial agglomeration; therefore, improving the industrial agglomeration level is the major way of improving China's environmental pollution. (2) Treating the function of industrial agglomeration on environmental pollution objectively; in the development course of industrial agglomeration level, the differentiated policy should be made for the different regions. In the region with low industrial agglomeration level, all appropriate measures can be taken to improve industrial agglomeration level and the direct investment of foreign merchant and severe environmental regulation can be used to improve environmental pollution and avoid from "pollution firstly and pollution governance secondly". In the region with high industrial agglomeration level, all appropriate measures, such as encouraging industrial technology innovation, optimizing industrial agglomeration direction, leading industrial agglomeration to develop toward high value-added industry (including highend R\&D and design) should be taken. (3) Encouraging to introduce foreign capital, formulate differentiated policy based on regional environmental pollution and industrial development level, lead foreign capital to transfer to clean industry, pay attention to attract foreign-owned enterprise having environmental technology advantages, use overseas advanced technology and environmental protection standard to achieve the dual objectives of capital attraction and environmental protection, and push China's economy to get high-quality development.

\section{ACKNOWLEDGEMENTS}

This work was financially supported by the Key Project of the National Social Science Foundation (18AJY013); the National Social Science foundation project (17CJY072; 19BJY236); The 2018 Fujian Social Science Planning Project (FJ2018B067); The Planning Fund Project of Humanities and Social Sciences Research of the Ministry of Education (19YJA790102); The Planning Project of Philosophy and Social Science of Zhejiang Province (18NDJC086YB).

\section{REFERENCES}

Almulali, U., Ozturk, I. and Lean, H. H. 2015. The influence of economic growth, urbanization, trade openness, financial development, and renewable energy on pollution in Europe. Nat. Hazards., 79(1): 621-644.

Baek, J., Cho, Y. and Koo, W. W. 2009. The environmental consequences of globalization: A country-specific time-series analysis. Ecol. Econ., 68(8): 2255-2264.

Frank, A. 2001. Urban air quality in larger conurbations in the European Union. Environ. Modell. Softw., 16(4): 399-414.

Lee, L. 2007. Gmm and 2SLS estimation of mixed regressive, spatial autoregressive models. J. Econom., 137(2): 489-514.

Ning, L. T., Wang, F. and Li, J. 2016. Urban innovation, regional externalities of foreign direct investment and industrial agglomeration: Evidence from Chinese cities. Res. Policy, 45(4): 830-843.

Ottaviano, G. I. P., Tabuchi, T. and Thisse, J. F. 2002. Agglomeration and trade revisited. Int. Econ. Rev., (43): 409-436.

Shao, S., Tian, Z. and Yang, L. 2017. High speed rail and urban service industry agglomeration: evidence from China's Yangtze River Delta region. J. Transp. Geogr., (64): 174-183.

Stiebale, J. 2011. Do financial constraints matter for foreign market entry? A firm-level examination. The World Economy, 34(1): 123-153. 
Venables, A. J. 1996. Equilibrium location of vertically linked industries. Int. Econ. Rev., 37: 341-359.

Virkanen, J. 1998. Effect of urbanization on metal deposition in the bay of Toolonlahti, southern of Finland. Mar. Pollut. Bull., 36(9): 729-738.

Walter, I. and Ugelow, J. L. 1979. Environmental policies in developing countries. Ambio., 8(2/3): 102-109.
Yamashita, N., Matsuura, T. and Nakajima, K. 2014. Agglomeration effects of inter-firm backward and forward linkages: Evidence from Japanese manufacturing investment in China. J. Jpn. Inst. Econ., 2014(34): 24-41.

Zeng, D. and Zhao, L. Pollution havens and industrial agglomeration. J. Environ. Econ. Manage., 58(2): 141-153. 